\title{
Increased Self-medication with Steroids in Inflammatory Bowel Disease Patients during COVID-19 Pandemic: Time to Optimize Specialized Telemonitoring Services
}

\author{
Gautam Vinay
}

\begin{abstract}
Inflammatory bowel disease (IBD) is a serious condition characterized by a complex interaction of genetic, environmental, and inflammatory variables that affect the gut and other extragastrointestinal systems. Self-medication with steroids has become a major issue in light of the current pandemic situation in IBD patients. We observed a higher frequency of steroid self-medication (17.9\%) and steroid overprescription (28.2\%) by non-gastroenterologists during the pandemic. The use of telemonitoring tools can improve patient-IBD care provider communications in terms of drug compliance and better disease outcomes.

Keywords: COVID-19, Inflammatory bowel diseases, Self-medication, Telemedicine.

Euroasian Journal of Hepato-Gastroenterology (2021): 10.5005/jp-journals-10018-1342
\end{abstract}

Inflammatory bowel disease (IBD) is a long-standing debilitating disease, which occurs due to complex interactions between genetic, environmental, and inflammatory processes affecting the gut and other extragastrointestinal systems. IBD includes ulcerative colitis (UC) and Crohn's disease (CD), accompanied by frequent relapse and remissions. Facing the coronavirus disease-2019 (COVID-19) pandemic has changed the current practice in IBD in terms of patient care and follow-up, although there is no current evidence that the severe acute respiratory syndrome coronavirus 2 (SARSCoV-2) exacerbates the underlying IBD. ${ }^{1}$ In a recent meta-analysis of 24 studies, the risk of SARS-CoV-2 infection in IBD is found to be equivalent to that of the general population. However, when compared to CD, UC has a higher risk of negative adverse outcomes, especially on steroids. ${ }^{2,3}$ Discontinuing current medications for IBD, such as 5-ASA, corticosteroids, immunomodulatory, and biological therapies, due to various reasons may trigger disease flare, disability, and dilemma to restart the therapy. Steroids are effective non-selective anti-inflammatory, immunomodulatory, vasoconstrictive, and anti-proliferative drugs. It is associated with several side effects even at modest dosages. ${ }^{4}$ Many studies have shown that a 5-year probability of receiving steroids is up to 75\% in IBD patients. ${ }^{5}$ European Crohn's and Colitis Organization (ECCO) guidelines recommend combining corticosteroids with 5-ASA preparations as first-line therapy in mild to moderate UC flares and moderate to severe ileocecal colonic $C D{ }^{6,7}$ The risk of severe infections, gastrointestinal bleed, osteoporosis, Cushing's syndrome, poor glycemic control, psychosis, sleep disturbances, hypertension, and delayed SARS-CoV-2 virus clearance are among adverse steroid effects. ${ }^{8}$

Self-medication is a major issue given the current pandemic situation, particularly in underdeveloped countries and having poor health infrastructure. Self-medication is defined by the World Health Organization as "the selection and utilization of medications to treat self-recognized symptoms or ailments without consulting a physician. ${ }^{\prime 9}$ Especially in IBD, the use of non-prescription drugs is common, notably corticosteroids, which are used by up to $15 \%$ of patients. ${ }^{10}$ According to a survey of 546 patients by Gismero et al.,
Department of Medical Gastroenterology, All India Institute of Medical Sciences, Rishikesh, Uttarakhand, India

Corresponding Author: Gautam Vinay, Department of Medical Gastroenterology, All India Institute of Medical Sciences, Rishikesh, Uttarakhand, India, Phone: +91 9915358392, e-mail: vinay3775@ gmail.com

How to cite this article: Vinay G. Increased Self-medication with Steroids in Inflammatory Bowel Disease Patients during COVID-19 Pandemic: Time to Optimize Specialized Telemonitoring Services. Euroasian J Hepato-Gastroenterol 2021;11(2):103-104.

Source of support: Kalinga Gastroenterology Foundation, Cuttack, Odisha, India.

Conflict of interest: None

self-medication was more prevalent among IBD patients when treated by general practitioners than IBD specialists $(p=0.007){ }^{11}$ Many studies have shown that having frequent disease flares, keeping the steroids after treatment completion, fear of symptom worsening, or to achieve quick symptom relief, preemptive prescription in case of flare by the primary care doctor, irregular follow-ups, electronic prescriptions, and ignorance of medications associated side effects were all factors related to self-medication behaviors. ${ }^{12}$ In our experience, 39 IBD (36 UC and 3 CD) patients were admitted at All India Institute of Medical Sciences, Rishikesh, India, between March 2020 and June 2021. The mean age of the study group was $39.6 \pm 14.1$ years, with a male predominance $(56.4 \%)$. We retrospectively observed that $46.1 \%$ (18/39) of the patients had received at least one dose of corticosteroids prior to the current admission to our center. Of these, $17.9 \%$ (7/39) patients had a history of self-medication with steroids, and $28.2 \%$ (11/39) patients had a prescription of steroids by non-gastroenterologists (Table 1).

\section{Specialized Telemedicine Services}

Telemedicine services are a popular approach that has shown promising results in IBD care, especially in times of the

(O) The Author(s). 2021 Open Access This article is distributed under the terms of the Creative Commons Attribution 4.0 International License (https://creativecommons. org/licenses/by-nc/4.0/), which permits unrestricted use, distribution, and non-commercial reproduction in any medium, provided you give appropriate credit to the original author(s) and the source, provide a link to the Creative Commons license, and indicate if changes were made. The Creative Commons Public Domain Dedication waiver (http://creativecommons.org/publicdomain/zero/1.0/) applies to the data made available in this article, unless otherwise stated. 
Table 1: Demographics and self-medication frequency with oral steroids

\begin{tabular}{lc}
\hline & $\%,(n=39)$ \\
\hline Age (mean \pm SD) & $39.6 \pm 14.1$ years \\
Male & $56.4 \%(22 / 39)$ \\
Female & $43.6 \%(17 / 39)$ \\
UC & $92.3 \%(36 / 39)$ \\
E1 & 0 \\
E2 & $47.2 \%(17 / 36)$ \\
E3 & $52.8 \%(19 / 36)$ \\
CD & $7.7 \%(3 / 39)$ \\
Number of prior hospital admissions [median (IQR)] & $2(1-3)$ \\
History of steroid use during the disease course & $74.3 \%(29 / 39)$ \\
Patients receiving steroids before the current admission & $46.1 \%(18 / 39)$ \\
Frequency of self-medication & $17.9 \%(7 / 39)$ \\
Steroid prescription by non-gastroenterologists & $28.2 \%(11 / 39)$ \\
\hline
\end{tabular}

COVID-19 pandemic. ${ }^{13,14}$ Although telemedicine services may not be equivalent to that of standard referral center care, it is a costeffective platform that can avoid unnecessary health center visits, particularly with the current travel restrictions. ${ }^{15}$ Telemonitoring interventions from IBD healthcare providers in the form of weekly assessment of symptoms, medication reconciliation, side effect profile monitoring, and specified action plans help monitor patients with active IBD symptoms. Further, integrating multidisciplinary IBD services, digging up previous records, identifying patients who need close follow-up, and actively contacting them will also help understand the disease course and prognosis better. In addition, IBDspecific knowledge can also be delivered through online lectures, instructional messages in local languages, teleconferencing, webbased group discussions, and IBD-specific applications. There is room for further development by exploring sophisticated virtual information delivery systems that are both affordable and accessible to the community. This provides the required attention and social support in patients with IBD, who often necessitate lifelong care. ${ }^{16}$

In conclusion, IBD management is confronted with additional problems during the COVID-19 pandemic. We observed a higher frequency of steroid self-medication (17.9\%) and steroid overprescription (28.2\%) by non-gastroenterologists. The use of telemonitoring systems will positively influence patient-IBD care provider communication, curbing misinformation, diseasemonitoring, and improve drug compliance.

\section{Author Contributions}

Conceptualization and original draft preparation: Budumuri Gautam V Kumar.

\section{References}

1. Derikx L, Lantinga MA, de Jong DJ, et al. Clinical outcomes of covid-19 in patients with inflammatory bowel disease: a nationwide cohort study. J Crohns Colitis 2021;15(4):529-539. DOI: 10.1093/ecco-jcc/ jjaa215.

2. Brenner EJ, Ungaro RC, Gearry RB, et al. Corticosteroids, but not TNF antagonists, are associated with adverse COVID-19 outcomes in patients with inflammatory bowel diseases: results from an international registry. Gastroenterology 2020;159(2):481-491.e3. DOI: 10.1053/j.gastro.2020.05.032.

3. Singh AK, Jena A, Kumar MP, et al. Risk and outcomes of coronavirus disease in patients with inflammatory bowel disease: a systematic review and meta-analysis. United European Gastroenterol J 2021;9(2):159-176. DOI: 10.1177/2050640620972602.
4. Rice JB, White AG, Scarpati LM, et al. Long-term systemic corticosteroid exposure: a systematic literature review. Clin Ther 2017;39(11):2216-2229. DOI: 10.1016/j.clinthera.2017.09.011.

5. Chhaya V, Saxena S, Cecil E, et al. Steroid dependency and trends in prescribing for inflammatory bowel disease - a 20-year national population-based study. Aliment Pharmacol Ther 2016;44(5): 482-494. DOI: 10.1111/apt.13700.

6. Magro F, Gionchetti P, Eliakim R, et al. Third European evidence-based consensus on diagnosis and management of ulcerative colitis. Part 1: definitions, diagnosis, extra-intestinal manifestations, pregnancy, cancer surveillance, surgery, and ileo-anal pouch disorders. J Crohn's Colitis 2017;11(6):649-670. DOI: 10.1093/ecco-jcc/jjx008.

7. Torres J, Bonovas S, Doherty G, et al. ECCO guidelines on therapeutics in Crohn's disease: medical treatment. J Crohn's Colitis 2019;14(1): 4-22. DOI: 10.1093/ecco-jcc/jjz180.

8. $\mathrm{Li} \mathrm{H}, \mathrm{Chen} \mathrm{C}, \mathrm{Hu}$ F, et al. Impact of corticosteroid therapy on outcomes of persons with SARS-CoV-2, SARS-CoV, or MERS-CoV infection: a systematic review and meta-analysis. Leukemia 2020;34(6):1503-1511. DOI: 10.1038/s41375-020-0848-3.

9. World Health O. Guidelines for the regulatory assessment of medicinal products for use in self-medication. Geneva: World Health Organization; 2000.

10. Filipe $V$, Allen PB, Peyrin-Biroulet L. Self-medication with steroids in inflammatory bowel disease. Dig Liver Dis 2016;48(1):23-26. DOI: 10.1016/j.dld.2015.10.010.

11. Mesonero Gismero F, Rodriguez-Lago I, Cañas M, et al. P571 selfmedication with steroids in ulcerative colitis: results of a patient survey. J Crohn's Colitis 2020;14(Supplement_1):S480-S481. DOI: 10.1093/ecco-jcc/jjz203.699.

12. Mesonero F, Juliá B, Saldaña R, et al. Self-medication with oral corticosteroids reported by patients with ulcerative colitis: characteristics, reasons and patients' behaviors. Eur J Gastroenterol Hepatol 2021;33(4). DOI: 10.1097/MEG.0000000000001931.

13. Quinn CC, Chard S, Roth EG, et al. The telemedicine for patients with inflammatory bowel disease (TELE-IBD) clinical trial: qualitative assessment of participants' perceptions. J Med Internet Res 2019;21(6):e14165. DOI: 10.2196/14165.

14. Pinto S, Loddo E, Paba S, etal.Crohn's disease and ulcerative colitis patientreported outcomes signs and symptoms for the remote management of inflammatory bowel disease during the COVID-19 pandemic. J Patient Rep Outcomes 2021;5(1):48. DOI: 10.1186/s41687-021-00323-z.

15. Del Hoyo J, Nos P, Faubel R, et al. A web-based telemanagement system for improving disease activity and quality of life in patients with complex inflammatory bowel disease: pilot randomized controlled trial. J Med Internet Res 2018;20(11):e11602. DOI: 10.2196/11602.

16. Abutaleb A, Buchwald A, Chudy-Onwugaje K, et al. Inflammatory bowel disease telemedicine clinical trial: impact of educational text messages on disease-specific knowledge over 1 year. Inflamm Bowel Dis 2018;24(10):2191-2197. DOI: 10.1093/ibd/izy149. 